\title{
Fracture behaviour of natural fibre reinforced composites
}

\author{
H. Takagi ${ }^{1} \&$ Y. Hagiwara ${ }^{2}$ \\ ${ }^{1}$ Institute of Technology and Science, The University of Tokushima, Japan \\ ${ }^{2}$ Graduate School of Engineering, The University of Tokushima, Japan
}

\begin{abstract}
This paper deals with the microfracture behaviour of natural fibre reinforced composite materials. The acoustic emission (AE) method was applied to detect various micro-scale energy release phenomena during tensile deformation not only of Manila hemp fibre, but also of three kinds of composites with three different fibre orientation angles, namely 0,45 , and 90 degree. In the case of Manila hemp fibre testing, low amplitude AE events (40-60 dB) are measured at an intermediate strain range, and high amplitude events are also measured at a final fracture stage. In the case of 0 degree composite, AE signals having a wide range of amplitude distribution are measured from the beginning of deformation, and the $\mathrm{AE}$ activity becomes significant with further tensile deformation. On the other hand, a few AE data with low amplitude are measured in 45 and 90 degree composites. In conclusion, low and high amplitude AE events observed during tensile deformation of natural fibre composites are derived from fibre splitting and fibre fracture, respectively.
\end{abstract}

Keywords: microfracture, acoustic emission, starch based resin, hemp fibre, fibre fracture, debonding.

\section{Introduction}

Recently, much of the research on natural fibre composites has been carried out in Europe, North America, and Asia and focused on the enhancement of their mechanical properties [1-13]. The natural fibre composites are the composite material that usually consists of biodegradable resin matrix mainly derived from natural resources and natural plant fibre as reinforcement. Therefore, they are derived from yearly renewable resources, and at the same time their disposal 
after usage becomes relatively easy. The natural fibre composite materials have been recognized as an environment-friendly material that can be substituted for conventional glass fibre reinforced plastics (GFRP). As various functions of natural fibre composites to be further noticed, the following are mentioned: strength characteristics, damping characteristics and sound-absorbing characteristics, which thereby allow the expanded application to various products.

However, the information on the microscopic fracture behaviour of natural fibre composites is still lacking, because of the many complicated factors affecting their fracture behaviour [14]. Three types of hemp fibre reinforced composite specimens ( 0,45 , and 90 degree composites), as well as neat resin specimens, were fabricated in this study. Their microscopic fracture behaviour was investigated using an acoustic emission (AE) method.

\section{Experimental methods}

\subsection{Materials}

A starch-based biodegradable resin (CP-300, Miyoshi Oil and Fat Co. Ltd., Japan) was used as a matrix resin [8-10]. This biodegradable resin is not pellettype, but dispersion-type. Fine starch-based biodegradable resin particles approximately $6 \mu \mathrm{m}$ in diameter are well dispersed in a water-based solution of pH 5.0 .

Manila hemp fibre was chosen as a reinforcing fibre due to its high performance in physical properties and availability $[8,10]$. The fibre diameter of the Manila hemp fibre is approximately $200 \mu \mathrm{m}$. It should be noted that this macroscopically single Manila hemp fibre consists of the hundreds of unidirectional single fibres.

\subsection{Fabrication method of three types of natural fibre reinforced composites with different fibre angles}

First of all, preliminary unidirectional composite sheets of approximately $100 \mathrm{x}$ $100 \mathrm{~mm}$ were prepared by putting the dispersion-type, biodegradable resin on the surface of unidirectionally aligned Manila hemp fibre sheets. These preliminary composite sheets were dried at $105^{\circ} \mathrm{C}$ for 2 hours in an oven. Then, these dried preliminary composite sheets were cut into three types of strips having different fibre angles of 0,45 , and 90 degrees, and of $10 \mathrm{~mm}$ width. These stripes obtained were stacked in a metallic mould and finally hot-pressed at $10 \mathrm{MPa}$ and $140^{\circ} \mathrm{C}$ for $10 \mathrm{~min}$. The final specimen size is $10.0 \times 100.0 \times 1.5 \mathrm{~mm}$. The fibre content of all specimens was fixed to be $50 \mathrm{wt} . \%$. Macroscopic views of the three types of specimens are shown in fig. 1 .

\subsection{Tensile tests with AE measurement}

We carried out quasi-static static tensile tests in order to evaluate the mechanical properties and microfracture behaviour of the hemp fibre reinforced composites. 
The tensile tests were conducted using a universal testing machine (5567, Instron Co., U.S.A) at room temperature. The cross-head speed and gauge length were $1.0 \mathrm{~mm} / \mathrm{min}$ and $40.0 \mathrm{~mm}$, respectively.

Two-channel AE measurement was simultaneously performed to evaluate the micro-scale damaging processes of natural fibre reinforced composites during tensile tests. Two AE sensors (F217M, Showa Electric Laboratory Co. Ltd.,

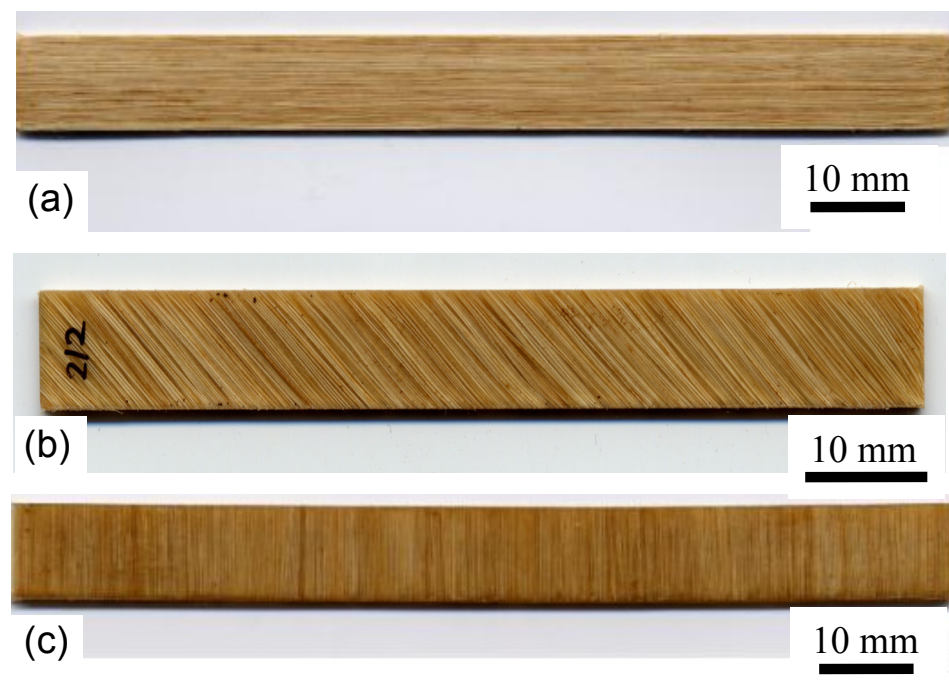

Figure 1: Macroscopic view of Manila hemp fibre reinforced composites: (a) 0 degree composite, (b) 45 degree composite, and (c) 90 degree composite.

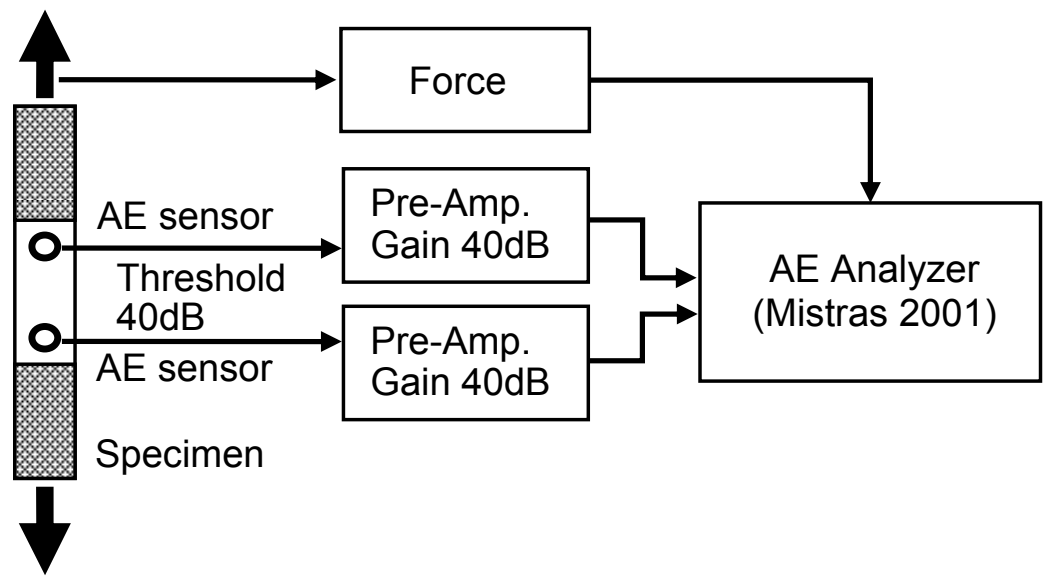

Figure 2: $\quad$ Two-channel AE signal measurement system. 
Japan) were attached on the specimen as shown in fig. 2. The distance between AE sensors was $30 \mathrm{~mm}$. The AE signals passed through a pre-amplifier (1220A, Physical Acoustics Co., U.S.A) with a gain of $40 \mathrm{~dB}$ were recorded in an $\mathrm{AE}$ analyzing system (MISTRAS 2001, Physical Acoustics Co., U.S.A). At the same time, tensile force information of the specimen was also recorded in the same AE analyzing system. The threshold value used in the AE measurement was set to be $40 \mathrm{~dB}$.

\subsection{Surface characterization}

The fracture morphology of the three kinds of hemp fibre composites and Manila hemp fibre was examined by optical microscope (SZH-10, Olympus Co., Japan) and field emission-type scanning electron microscope (SEM: S-4700, Hitachi Ltd., Japan). All samples were sputter-coated with gold using a sputter coater (E1010, Hitachi Ltd., Japan) prior to SEM observation.

\section{Experimental results and discussion}

\subsection{Deformation and fracture behaviour of Manila hemp fibre}

The AE event diagram for Manila hemp fibre is shown in fig. 3. The stressstrain curve of Manila hemp fibre is also demonstrated in the same graph. Tensile strength of Manila hemp fibre reaches a value higher than $800 \mathrm{MPa}$,

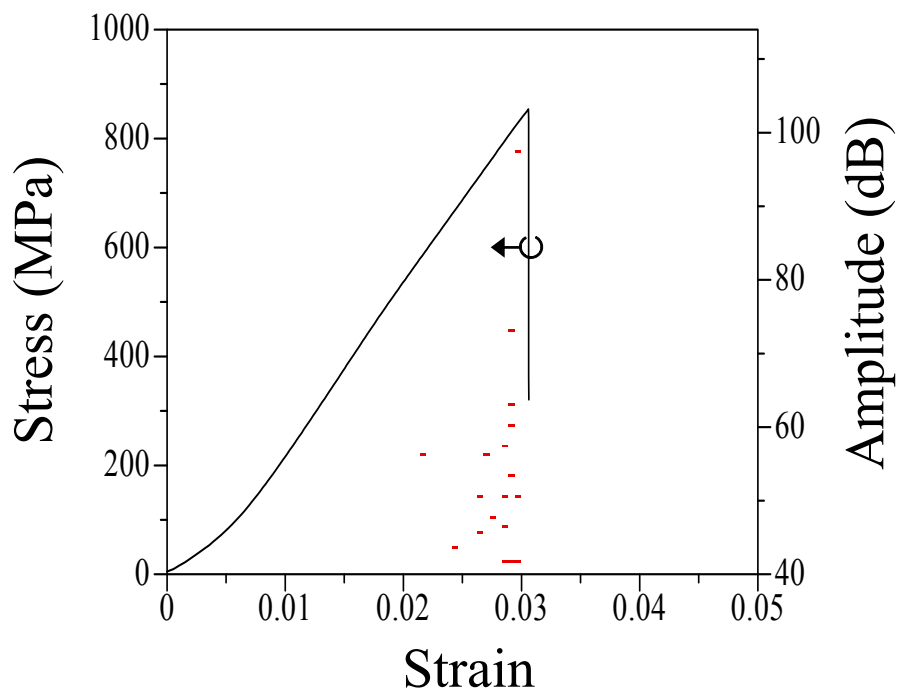

Figure 3: $\quad$ Stress-strain diagram of Manila hemp fibre with AE activities. 


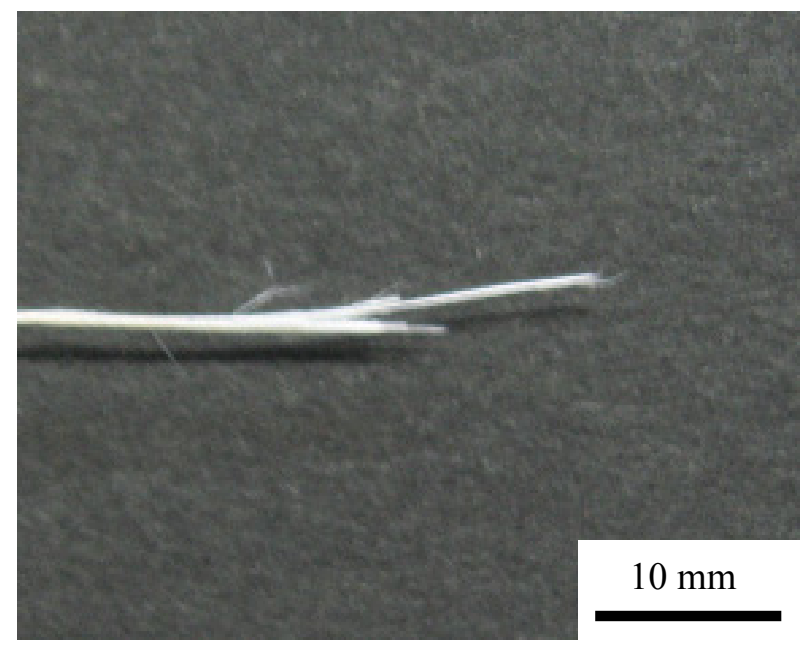

Figure 4: $\quad$ Fracture behaviour of Manila hemp fibre.

showing excellent mechanical properties. It can be seen that relatively low amplitude AE events $(40-60 \mathrm{~dB})$ are measured at an intermediate strain range $(\varepsilon=0.02)$ and that high-amplitude $\mathrm{AE}$ events are also measured just before final fibre fracture. Furthermore, Manila hemp fibre is split into many single fibres as shown in fig. 4. From these results, we found that high-amplitude AE events are derived from the fracture of single fibre, and that low amplitude AE events might be derived from fibre splitting among the single fibres. Similar fracture behaviour of natural fibre has been reported in flax fibre reinforced composites [15].

\subsection{Tensile properties of Manila hemp fibre-reinforced composites}

\subsubsection{0 degree composite}

Stress-strain curve with AE activities of the 0 degree composite is represented in fig. 5. Many AE events having a wide amplitude distribution; i.e. from low amplitude to high amplitude, are measured from the early stage of tensile deformation to final composite fracture [16]. It should be noted that relatively high amplitude AE events are frequently observed even at the beginning of the deformation process. This strain range is much smaller than fracture strain of Manila hemp fibres themselves as shown in fig. 3. It is therefore suggested that this AE event is derived from the microfracture of pre-damaged Manila hemp fibres. Some damages might be introduced into Manila hemp fibre during its extraction process or composites' fabrication process. Low amplitude AE events less than $60 \mathrm{~dB}$ are also often found in the middle of deformation process. These low AE events seem to be derived from matrix deformation and fracture or fibrematrix debonding [17]. However, no AE event was detected during tensile deformation of neat resin. Hence the low AE events are presumably derived from fibre-matrix debonding. 


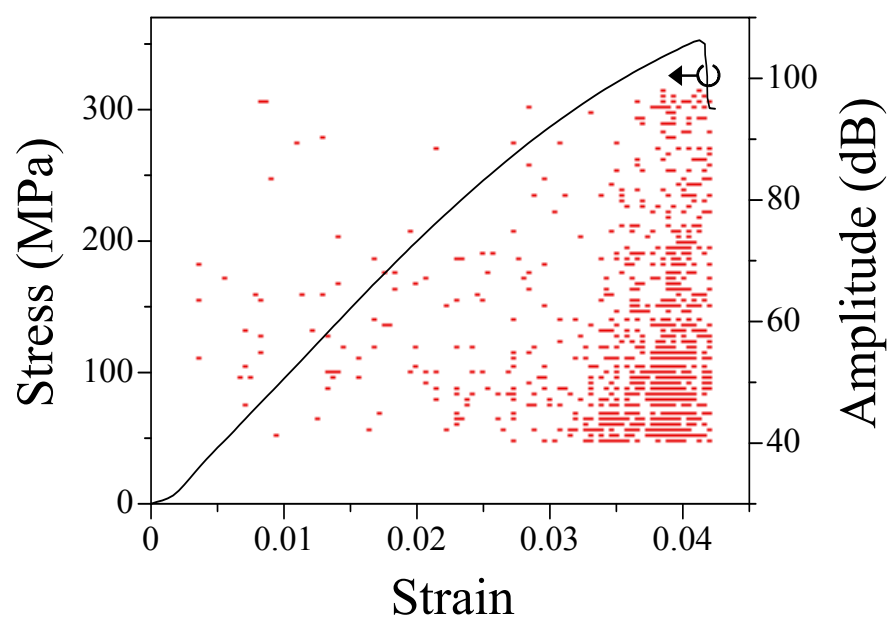

Figure 5: Stress-strain diagram of 0 degree composite with AE activities.

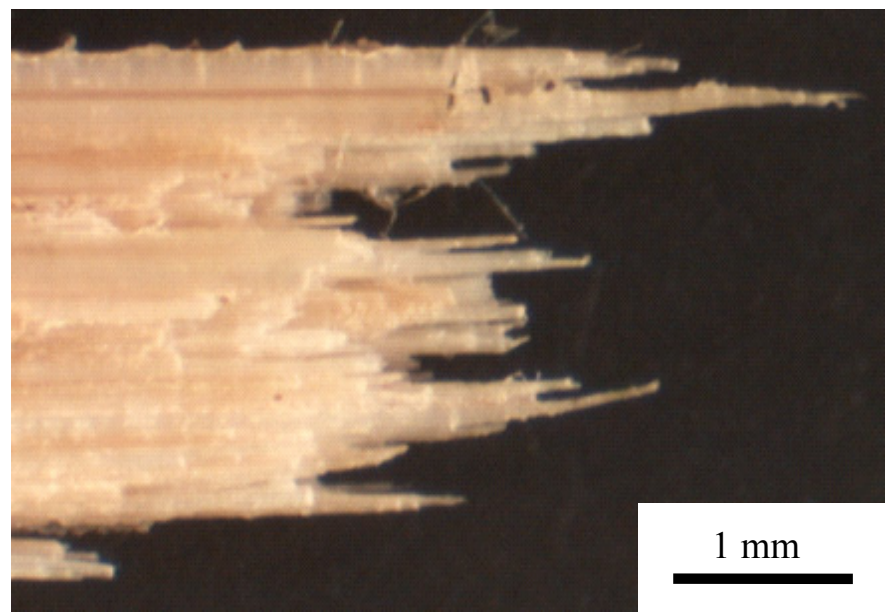

Figure 6: Fracture surface of 0 degree composite, showing many pull-out fibres.

Figure 6 depicts the fracture surface of 0 degree composite. It can be seen that there are many pull-out fibres on the fracture surface and that the interfacial fracture also occurs extensively.

\subsubsection{5 degree composite}

Stress-strain curve with AE activities of the 45 degree composite is shown in fig. 7. It can be seen from this figure that many low amplitude AE events are observed during deformation and that the deformation stress of 45 degree 
composite is only $12 \mathrm{MPa}$, which is almost equivalent to that of neat resin. In addition, these composites exhibit ductile behaviours with high fracture strain. Figures 8 and 9 represent the fracture behaviour of this composite. It can be seen that the composites is fractured in a shear mode and that the fracture is governed by interfacial debonding.

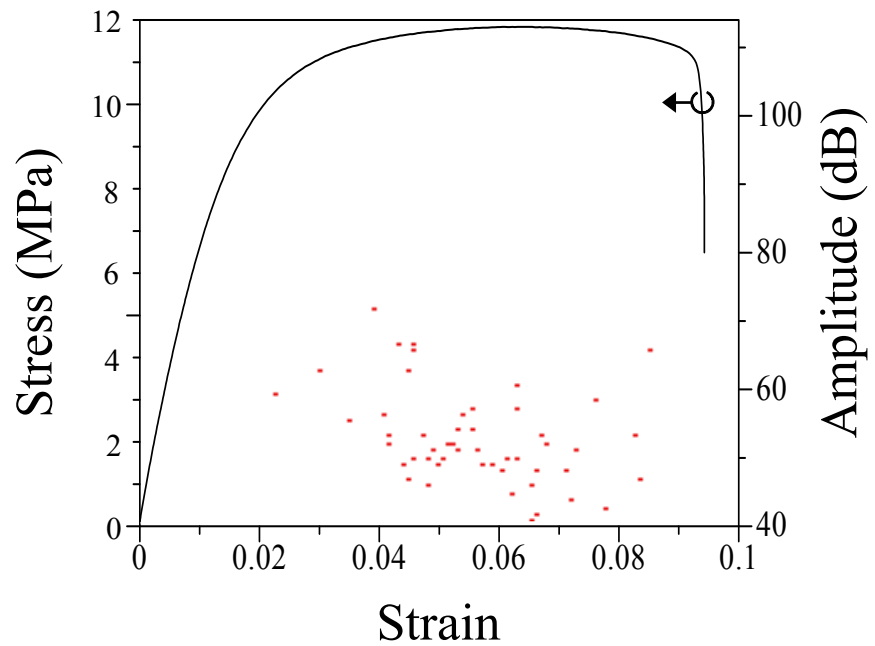

Figure 7: Stress-strain diagram of 45 degree composite with AE activities.

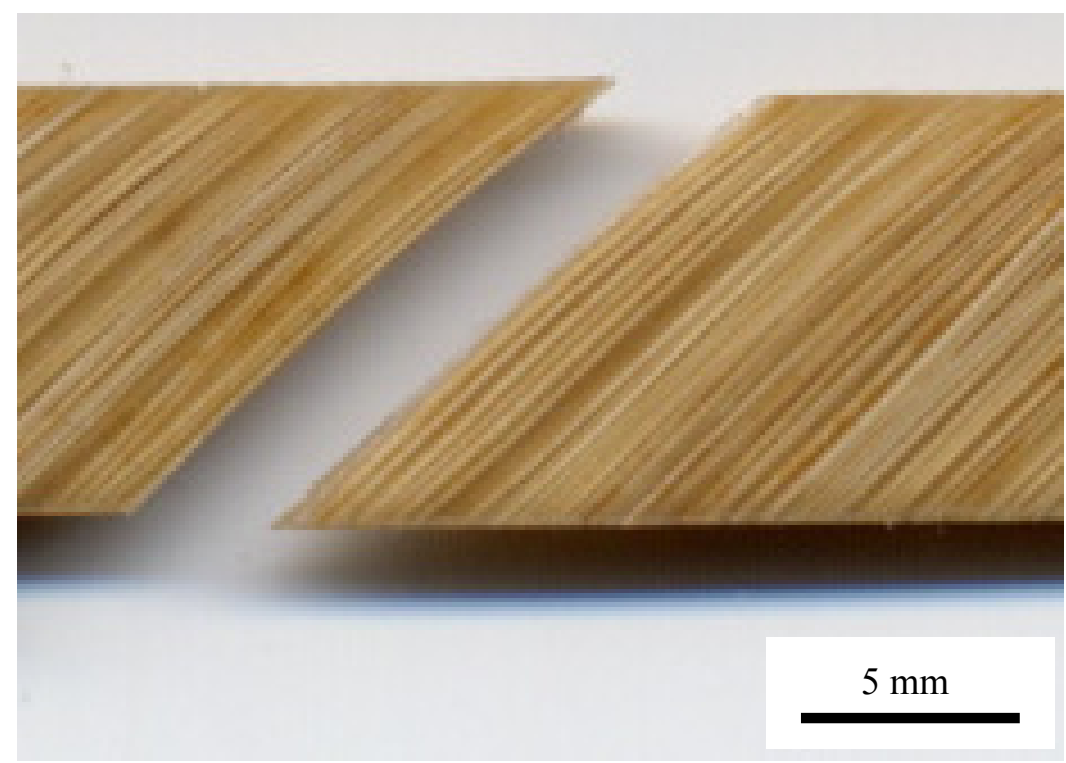

Figure 8: Fracture surface of 45 degree composite, showing a shear fracture mode. 


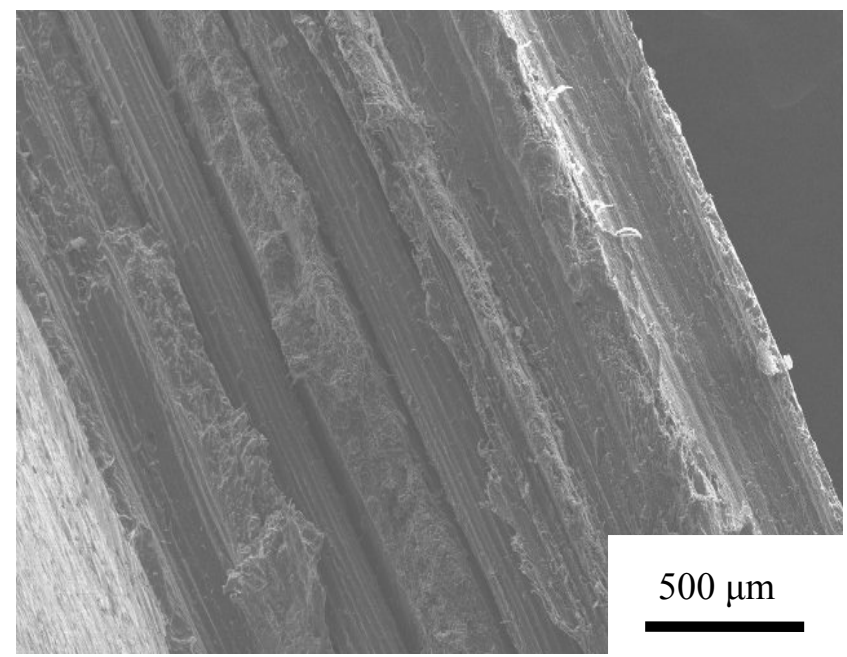

Figure 9: Fracture surface of 45 degree composites, showing interfacial fracture between resin and fibre.

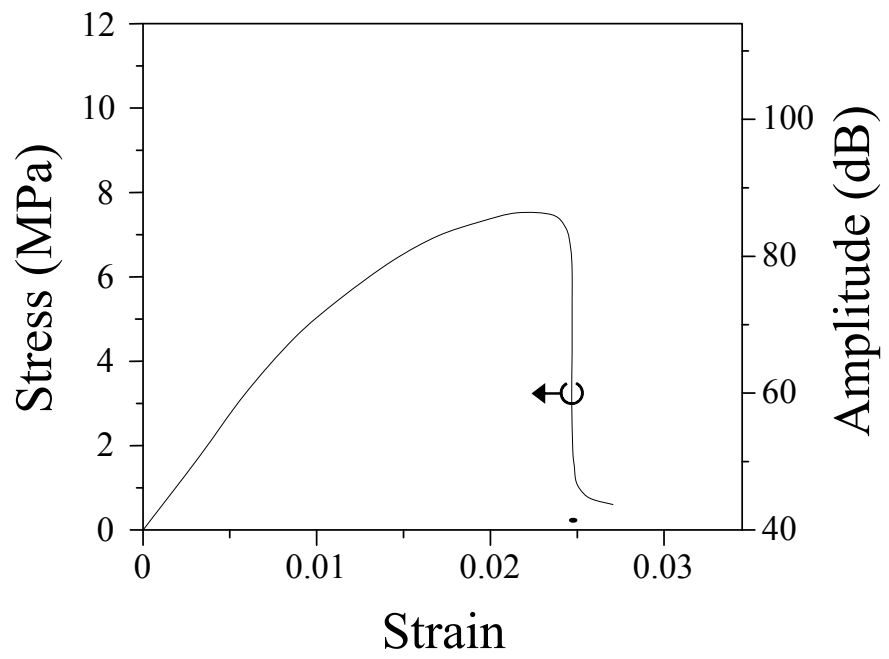

Figure 10: Stress-strain diagram of 90 degree composite with AE activities.

\subsubsection{0 degree composite}

Stress-strain curve with AE activities of the 90 degree composite is shown in fig. 10 . On the contrary, there is only one AE event with very low amplitude at around the final fracture. Microscopic view of fracture surface of 90 degree composite is shown in fig. 11. In this case an interfacial fracture between matrix resin and reinforcing fibre governed the final fracture. Therefore, it is demonstrated that $\mathrm{AE}$ event generated from interfacial fracture has relatively low amplitude and that a few $\mathrm{AE}$ events occur during the entire deformation. 


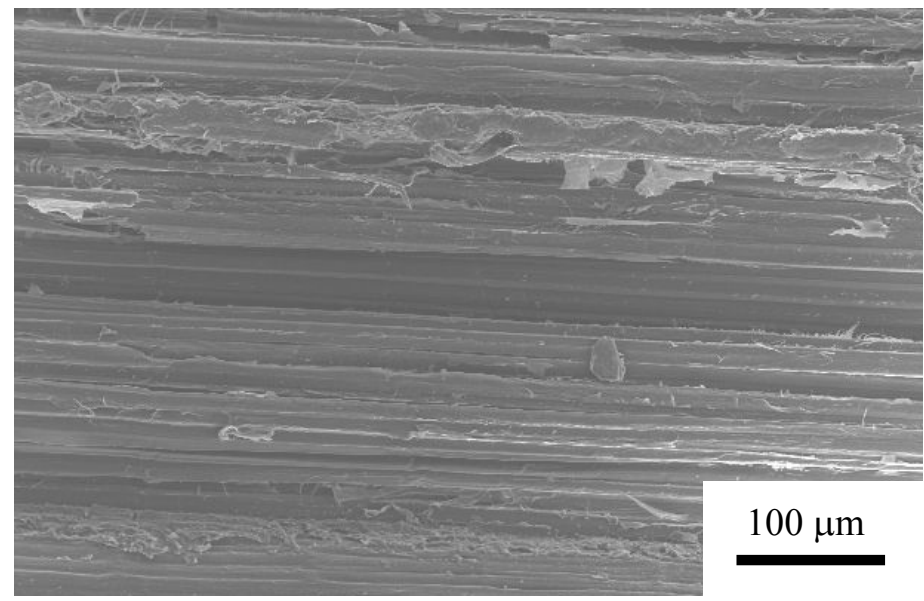

Figure 11: Fracture surface of 90 degree composites, showing interfacial fracture between resin and fibre.

\section{Conclusions}

In summary, in the case of 0 degree composite, $\mathrm{AE}$ events having a wide range of amplitude distribution are measured from the beginning of deformation, and $\mathrm{AE}$ activities become pronounced with further deformation. On the other hand, a few AE events with low amplitude are measured in 45 and 90 degree composites. These results suggest that low amplitude events and high amplitude $\mathrm{AE}$ events are derived from fibre splitting and fibre fracture, respectively.

\section{References}

[1] Wollerdorfer, M. \& Bader, H., Influence of natural fibres on the mechanical properties of biodegradable polymers. Industrial Crops and Products, 8(2), pp. 105-112, 1998.

[2] Luo, S. \& Netravali, A. N., Interfacial and mechanical properties of environment-friendly "green" composites made from pineapple fibers and poly(hydroxybutyrate-co-valerate) resin. Journal of Materials Science, 34(15), pp. 3709-3719, 1999.

[3] Luo, S. \& Netravali, A. N., Mechanical and thermal properties of environment-friendly green composites made from pineapple leaf fibers and poly(hydroxybutyrate-co-valerate) resin. Polymer Composites, 20(3), pp. 367-378, 1999.

[4] Lodha, P. \& Netravali, A. N., Characterization of interfacial and mechanical properties of "green" composites with soy protein isolate and ramie fiber. Journal of Materials Science, 37(17), pp. 3657-3665, 2002.

[5] Netravali, A. N. \& Chabba, S., Composites get greener. Materials today, 6(4), pp. 22-29, 2003. 
[6] Mohanty, A. K., Misra, M. \& Hinrichsen, G., Biofibres, biodegradable polymers and biocomposites: An overview. Macromolecular Materials and Engineering, 276/277(1), pp. 1-24, 2000.

[7] Mueller, D. H. \& Krobjilowski, A., New discovery in the properties of composites reinforced with natural fibers. Journal of Industrial Textiles, 33(2), pp. 111-130, 2003.

[8] Takagi, H. \& Ochi, S., Characterization of high-strength "green" composites using Manila hemp fibers and starch-based resin. Proceedings of the Third Japan-Canada Joint Conference on New Applications of Advanced Composites (JCJC-III), pp. 19-27, 2003.

[9] Takagi, H. \& Ichihara, Y., Effect of fiber length on mechanical properties of "green" composites using a starch-based resin and short bamboo fibers. JSME International Journal, Series A, 47(4), pp. 551-555, 2004.

[10] Takagi, H., Biodegradation behavior of starch-based "green" composites reinforced by Manila hemp fiber. Proceedings of Third International Conference on Eco-Composites, pp. 14-1-14-6, 2005.

[11] Takagi, H. Kako, S. Kusano, K. \& Ousaka, A., Thermal conductivity of PLA-bamboo fiber composites. Advanced Composite Materials, 16(4), pp. 377-384, 2007.

[12] Takagi, H. \& Asano, A., Effects of processing conditions on flexural properties of cellulose nanofiber reinforced "green" composites. Composites Part A, 38(4), pp.685-689, 2008.

[13] Tokoro, R. Vu, D. M. Okubo, K. Tanaka, T. Fujii, T. \& Fujiura, T., How to improve mechanical properties of poly lactic acid with bamboo fibers. Journal of Materials Science, 43(2), pp. 775-787, 2008.

[14] De Rosa, I. M., Santulli, C. \& Sarasini, F., Acoustic emission for monitoring the mechanical behaviour of natural fibre composites: A literature review. Composites Part A, 40(9), pp. 1456-1469, 2009.

[15] Romhany, G., Karger-Kocsis, J. \& Czigany, T., Tensile fracture and failure behavior of thermoplastic starch with unidirectional and cross-ply flax fiber reinforcements. Macromolecular Materials and Engineering, 288(9), pp. 699-707, 2003.

[16] Shin, F.G. Xian, X.J. Zheng, W.G. \& Yipp, M.W., Analysis of the mechanical properties and microstructure of bamboo-epoxy composites. Journal of Materials Science, 24(10), pp. 3483-3490, 1989.

[17] Park, J-M. Kim, P-G. Jang, J-H. Wang, Z. Hwang, B-S. \& DeVries, K. L., Interfacial evaluation and durability of modified Jute fibers/polypropylene (PP) composites using micromechanical test and acoustic emission. Composites Part B, 39(6), pp. 1042-1061, 2008. 